\section{$006-007$ \\ Noticias y comentarios \\ PH51 - Diciembre 2004}

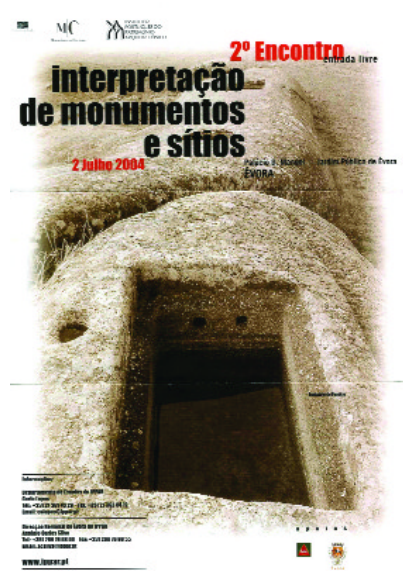

Póster informativo

\title{
¿Qué lugar ocupa la interpretación en la difusión del patrimonio?
}

El Palacio D. Manuel de Évora (Portugal) acogió el pasado 2 de julio el $2^{\circ}$ Encuentro sobre Interpretación de Monumentos y Sitios, organizado por el IPPAR (Instituto Português do Património Arquitectónico) con la finalidad de promover la reflexión y el debate sobre la temática de la interpretación del patrimonio y para definir el lugar que puede ocupar la interpretación en las estrategias de puesta en valor y difusión del patrimonio.

El encuentro reunió doce comunicaciones, agrupadas en función de las tipologías patrimoniales abordadas o la metodología empleada:

> Áreas territoriales extensas: "Circuitos arqueológicos de Antas de Elvas", por Ana Carvalho Dias, e "Interpretación en el Parque Natural de las Sierras de Aire y Candeeiros", por Maria João Botelho. En el caso de los circuitos arqueológicos fue posible obtener una lectura global de una experiencia pionera ya consolidada, partiendo de los objetivos y conceptos iniciales del proyecto; en el caso del Parque Natural, se tuvo la oportunidad de confrontar aquellas cuestiones propias de la interpretación a una escala territorial extensa, en una realidad socioeconómica regional, con las complejidades e interdependencias institucionales que ello conlleva, permitiendo situar y avalar las potencialidades de los valores culturales en este tipo de contextos.

> Sitios arqueológicos: "Tongóbriga, unidad arqueológica de Freixo", por Lino Tavares Dias, enfocó un ejemplo ya modélico de proyecto integral de investigación / educación / gestión / interpretación en el marco de una pre-ocupación territorial extensa en el contexto actual; "Sitio Arqueológico de S. Cucufate", por Rafael Alfenim, dio cuenta de un proyecto de gestión integral de un sitio arqueológico que focaliza la comunicación en la utilización de herramientas de interpretación basadas en reconstrucción virtual; "Castelo Velho de Freixo de Numão", por Miguel Rodrigues y Alexandre Alves Costa, abordó la necesidad y pertinencia del debate de la dimensión arquitectónica en los procesos de valoración e interpretación, y "Santuario de Panóias", por Orlando Sousa, aportó la perspectiva de la utilización del soporte digital en la presentación e interpretación de un sitio.

$>$ Monumentos aislados: por otro lado, "Castillo de Algoso", por Paulo Amaral, estuvo centrado en el caso particular del proyecto de valorización de un monumento localizado en un contexto claramente aislado, con problemáticas, estrategias conceptuales y de materialización concretas.

> Palacios: "Palacio de los Duques de Braganza", en Guimaraes, por Jorge da Costa, presentó un esquema conceptual integrado de la interpretación y gestión espacial de un palacio.
$>$ Monumentos en estado de obra: "Monasterio de Santa-Clara-a-Velha", en Coimbra, por Artur CôrteReal, comentó un caso singular de apertura al público de un monumento en estado de intervención, que ofrece la oportunidad de estructurar acciones didácticas sobre los procesos de recuperación y puesta en valor de un recurso como modo de sensibilización para la salvaguarda de monumentos.

Tres intervenciones marco centraron las cuestiones relativas a la interpretación: "Resituar el patrimonio de cara al público, o el papel de la interpretación", a cargo de Manuel Lacerda, quien situó la posición del patrimonio en la sociedad contemporánea y la importancia de la interpretación en el papel actual de los monumentos y sitios en cuanto que recurso insustituible para la comunidad; "Después de los Itinerarios Arqueológicos del Alentejo y Algarve", título de la ponencia con la que Filomena Barata hizo un balace de este programa desarrollado por el IPPAR entre 1994 y 2002, poniendo hincapié en las perspectivas de evolución y amenazas y llamando la atención sobre la necesidad de mayores interrelaciones entre diferentes realidades patrimoniales en un determinado contexto patrimonial, y, finalmente, "Acerca de la sostenibilidad de las intervenciones de valorización de los sitios arqueológicos", donde Rui Parreira expuso un balance de riesgos y beneficios de las acciones de puesta en valor de los sitios arqueológicos.

En términos generales, el encuentro permitió reafirmar la importancia del desarrollo del debate acerca de la interpretación, entendida de un modo lato e inserparable del debate acerca de los modelos de gestión y su sostenibilidad; aclarar la necesidad de una percepción rigurosa de las finalidades de la interpretación en la sociedad actual y la necesidad de adecuación de conceptos, estrategias y fines en consonancia con esa realidad compleja y mutable; advertir sobre los riesgos de banalización y los riesgos de destrucción potencialmente contenidos en los procesos de valorización y presentación pública de sitios y monumentos; constatar la diversidad y la especificidad de exigencias requeridas por las diferentes tipologías patrimoniales y por las respectivas escalas de intervención, sugiriendo abordamientos y debates más especializados; y constatar la urgencia de una perspectiva cada vez más integradora de las diferentes opciones disciplinares sobre la interpretación de los monumentos (una visión holistica y transdisciplinar).

Manuel Lacerda

Arquitecto y Director del Departamento de Estudios del IPPAR 